\title{
PSYCHOMETRIC VALIDATION OF THE REINTEGRATION TO NORMAL LIVING INDEX IN PEOPLE LIVING WITH SPINAL CORD INJURIES
}

\begin{abstract}
The evaluation of rehabilitation outcomes requires measurement instruments that are valid and reliable, and have been psychometrically tested in the context of a particular population. The purpose of this study was to psychometrically test the validity and reliability of the Reintegration to Normal Living Index (RNLI) as a measure of community reintegration in a population of community-dwelling people living with spinal cord injury (PLWSCI) in South Africa.

The study was a cross-sectional, involving community dwelling people living with SCI (PLWSCI), who had been discharged from inpatient rehabilitation at for at least two years. RNLI data collected from 160 PLWSCI were subjected to factor analysis and tested for reliability using chronbach's alpha.

Cronbach's alpha for the RNLI instrument was 0.97 (ICC 95\% CI: 0.97 - 0.98), indicating an excellent reliability coefficient. A single -factor structure emerged from principal components analysis, indicating that there is only one factor structure for the RNLI in this population of PLWSCI. The content, construct, convergent and discriminate validity of the instrument were established.

The results of this study support the reliability and factorial validity of the RNLI as a measure of community reintegration for PLWSCI. The RNLI is therefore a valuable outcome measure and should be extended to other SCI rehabilitation studies in South Africa.
\end{abstract}

\section{KEY WORDS: SPINAL CORD INJURY, REHABILITATION, PARTICIPATION, PSYCHOMETRIC TESTING.}

\section{INTRODUCTION}

A spinal cord injury (SCI) is a devastating condition which results in enormous personal and psychosocial consequences. People living with SCI (PLWSCI) have to cope with various challenges, of which adapting to community life is one of the greatest. The main challenge for PLWSCI starts when they return home after institutionalised rehabilitation. These challenges usually manifest in the form of reintegration into and participation in their communities. Community reintegration is the most meaningful outcome of rehabilitation, as it relates to real life issues in the community (Cicerone 2004).

The evaluation of rehabilitation outcomes (like community reintegration) requires measurement instruments that are valid and reliable, and have been psychometrically tested in the context of a particular population (Magasi, et al 2008). Outcome measurement provides information of any change in a patients' health status from one point in time to another (Greenhalgh et. al 1998). As evidence based and outcome orientated professionals, physiotherapists use outcome measures, in different context for different reasons. In the academic context, outcome measures provide useful research information. Clinicians can describe, predict and evaluate the condition of the patient progress using appropriate outcome measures which reflect on the effectiveness of clinical interventions (Wade 2004).

Numerous instruments have been developed for measuring community reintegration, including the Return to Normal Living Index (RNLI). The Reintegration to Normal Living Index (RNLI) assesses the consequences of a health condition/disease upon the resumption of normal life (Daneski et al 2003). The RNLI has not, however, been tested in South Africa. Good practice requires that the psychometric properties of an instrument be re-evaluated each time the instrument is used in a new setting (e.g. different country) or with a different group of people than that for which it was originally designed for (Djikers 1999 Streiner and Norman 1989). Therefore the purpose of this study was to evaluate the psychometric properties of the RNLI, in a group of South African PLWSCI.

\section{METHODOLOGY}

This psychometric analysis was part of a large cross sectional quantitative study that evaluated participation outcomes in PLWSCI (Mothabeng 2011).

\section{Correspondence Author:}

DJ Mothabeng

Physiotherapy Department,

University of Pretoria,

South Africa

Email: Joyce.mothabeng@up.ac.za 


\section{Participants}

Potential participants were identified from the databases of two rehabilitation centres in the Tshwane metropolitan area, Gauteng province, South Africa. One hundred and sixty volunteer participants constituted the sample of convenience. The sample size of 160 participants was determined using principles of factor analysis which require a minimum of ten participants per item (Coakes and Steed 1996 Nunnally 1978). Although the RNLI has 11 items and would require a minimum of 110 participants, the main study factor analysed a number of instruments, with the longest having 16 items; hence the sample size was 160 (16 X 10).

\section{Measurements}

Community reintegration was measured using the Reintegration to Normal Living (RNL) Index (Wood-Dauphinee et al 1988). The RNLI is an 11-item instrument questionnaire developed to measure how people living with chronic conditions (like SCI) perceive and/or are satisfied with their reintegration into society in terms of functional activities of daily life, social and recreational activities, and interactions with people. The items of the RNLI are reflected in the results (Table 1 and 2).
To score the RNLI, participants are asked to rate on a 4 point $(1-4)$ Likerttype scale (Panget al 2007) how much they agreed with the various RNLI statements. The total scores range from $11-44$. The scores for the items are summed and then expressed as a percentage, with higher scores indicating a higher level of satisfaction (WoodDauphinee et al 1988). A study to establish the validity and reliability of the RNLI in a population of community-dwelling adults with mobility limitations (Stark et al 2005)) found the RNLI has excellent internal consistency $($ Crohnbach alpha $=0.91)$.

\section{DATA ANALYSIS}

The analyses were computed using the version 17.0 of the Statistical Package for the Social Sciences (SPSS 17). The internal consistency of the RNLI factors was determined using the Cronbach's alpha coefficients (Arias and de Vos 1996 Cronbach, 1970 George and Mallery 2003 Nunnally 1978). Factor analysis was done using Principal components analysis with Varimax rotation to identify the underlying dimensions and factor structure of the RNLI.

Content validity of the RNLI was established the Kaiser-Meyer-Olkin measure of item sampling adequacy (Child 1970 Kaiser 1974 Nunnally 1978). The construct validity of the RNLI was established through principal components analysis, (Andaleeb 2001). Item convergent validity was determined by the inter-correlations of individual items and the instrument correlation co-efficient. The criterion for corrected item-total correlation coefficients was set at $r>0.40$ (Stewart et al 1988). Item discriminant validity was established using the Fisher's z-test (Rosner 1986).

\section{RESULTS}

The results of the psychometric analysis of the RNLI data from 160 PLWSCI, 134 males and 26 females with a mean age of $29.19+/-8.05$ are presented below.

\section{Reliability}

Cronbach's alpha for the RNLI instrument was 0.974 (ICC 95\% CI: 0.97 -0.98 ), which is regarded as an excellent reliability coefficient (Arias and de Vos 1996 George and Mallery 2003). Elimination of any of the items in the RNLI resulted in a slight decrease of the coefficient alpha of the scale.

\section{APPENDICES}

Table 1. Item convergent validity for the RNLI

\begin{tabular}{|l|l|l|l|}
\hline RNLI ITEMS & $\begin{array}{l}\text { Scale Variance } \\
\text { if Item Deleted }\end{array}$ & $\begin{array}{l}\text { Corrected Item- } \\
\text { Total Correlation } \\
\text { (r) }\end{array}$ & $\begin{array}{l}\text { Cronbach's } \\
\text { Alpha if Item } \\
\text { Deleted }\end{array}$ \\
\hline I move around my living quarters as I feel necessary & 86.712 & .899 & .971 \\
\hline I move around my community as I feel necessary & 86.032 & .894 & .971 \\
\hline I am able to make trips out of town as I feel necessary & 88.011 & .730 & .975 \\
\hline I am comfortable with how my self care needs are met & 87.441 & .843 & .972 \\
\hline I spend most of my day occupied in work activity important to me & 84.153 & .860 & .972 \\
\hline I am able to participate in recreational activities as I want to & 84.761 & .825 & .973 \\
\hline $\begin{array}{l}\text { I participate in social activities with my family, friends and/or } \\
\text { business acquaintances as is necessary or desirable to me }\end{array}$ & 84.711 & .907 & .970 \\
\hline $\begin{array}{l}\text { I assume a role in my family which meets my needs and those of the } \\
\text { other family members }\end{array}$ & 84.679 & .900 & .970 \\
\hline In general I am comfortable with my personal relationships & 85.809 & .889 & .971 \\
\hline $\begin{array}{l}\text { In general I am comfortable with myself when I am in the company } \\
\text { of others }\end{array}$ & 85.814 & .924 & .970 \\
\hline I feel that I can deal with life events as they happen & & 892 \\
\hline
\end{tabular}


Table 2: RNLI factor structure

\begin{tabular}{|l|l|}
\hline RNLI items & Factor 1 \\
\hline I move around my community as I feel necessary & .915 \\
\hline I am able to make trips out of town as I feel necessary & .776 \\
\hline I am comfortable with how my self care needs are met & .859 \\
\hline I spend most of my day occupied in work activity important to me & .889 \\
\hline I am able to participate in recreational activities as I want to & .856 \\
\hline $\begin{array}{l}\text { I participate in social activities with my family, friends and/or business acquaintances as is necessary or } \\
\text { desirable to me }\end{array}$ & .927 \\
\hline I assume a role in my family which meets my needs and those of the other family members & .923 \\
\hline In general I am comfortable with my personal relationships & .912 \\
\hline In general I am comfortable with myself when I am in the company of others & .941 \\
\hline I feel that I can deal with life events as they happen & .916 \\
\hline
\end{tabular}

Figure 1: Scree plot of the of the Eigen values from the RNLI factor analysis

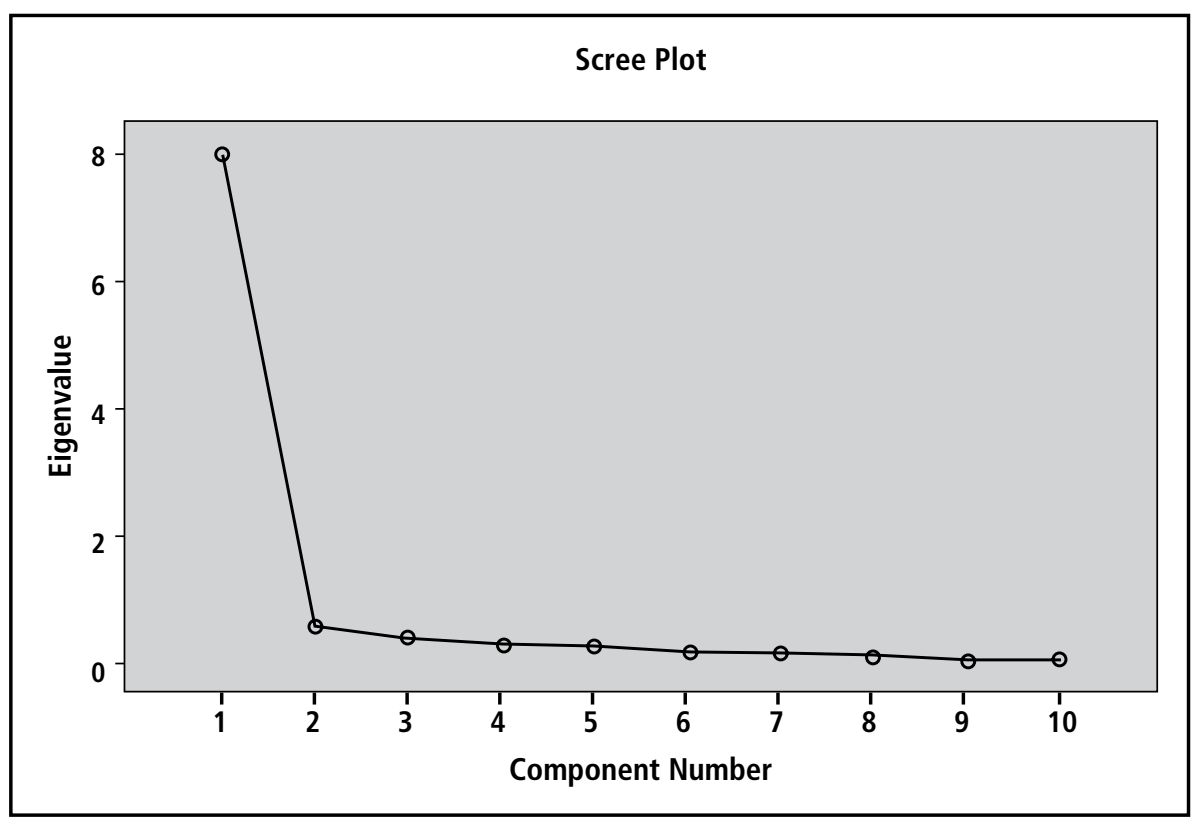

\section{Factor analysis}

The Kaiser-Meyer-Olkin (KMO) analysis of the $11 \mathrm{X} 11$ correlation matrix of the RNLI resulted in a sampling adequacy of 0.90 , which is greater than the 0.50 cut-off (Kaiser 1974). The Bartlett's test of sphericity (Chi-square $=2174.83$, $\mathrm{df}=45, \mathrm{p}<0.001)$ also indicated that it was appropriate to proceed with factor analysis. The Kaiser-Guttman rule for Eigen values greater than one (Gorush 1983) and the Cattell's scree test (Cattell 1966) indicated a single-factor solution for the scale (figure 1; and table 2) which accounted for $79.7 \%$ of the total variance.

\section{Validity}

Inspection of the means and standard deviations for the 11 items revealed minimum variation, suggesting roughly equivalent means and variance; thereby satisfying the first criterion for convergent validity (Stewart et al 1988). Corrected RNLI item-total correlation coefficients ranged from 0.73 to 0.91 as shown in Table 2; satisfying the criterion ( $\mathrm{r} \geq 0.40$ ) for item convergent validity (Stewart et al 1988). Fisher's $\mathrm{z}$ value was found to be 4.45 , which is greater than 1.96 , the criterion for $z$. Therefore item discriminant validity of the RNLI was established (Kim \& Mueller, 1978). Item loadings ranged between 0.86 and $0.93(>0.71)$ on all the items, providing support for the construct validity of the RNLI as a pure measure of community reintegration (Tabachnick and Fidell 1996) in this sample of PLWSCI.

\section{DISCUSSION}

This paper examined the validity and reliability of the RNLI as a measure of community reintegration in a population of South African PLWSCI. The RNLI was found to be reliable, with a Cronbach's alpha of 0.97 , which is regarded as an excellent reliability coefficient. Similar results were reported by Stark, Edwards, Hollingsworth and Gray (2005) who found the RNLI to have a Cronbach alpha value of 0.91 . The high internal consistency of the RNLI indicates that the items on the instrument are homogenous, that is, they are all measuring the same attribute. The decrease in Cronbach's alpha when eliminating any of the items indicated that all items contribute to the homogeneity of the scale. This homogeneity was further confirmed by the corrected itemtotal correlation coefficients (r-values), which were above the recommended value of 0.40 (Stewart et al 1988).

In this study, a single factor structure of the RNLI was identified. This finding suggests that all the RNLI items measure the same concept, and are relevant to the diversity in the sub classifications of spinal cord injuries, which are often unique in the functional limitations and participation restrictions that are experienced.

The single factor structure found in this study differs from what has been reported in other studies. For example, the developers of the RNLI instrument (Wood-Dauphinee et al 1988) identified two subscales to the RNLI namely: Daily Functioning (indoor, community, 
and distance mobility, self-care; daily activity (work and school), recreational and social activities, and general coping skills) and Perception of Self (family role(s), personal relationships, and presentation of self to others.). On the other hand, Stark et al (2005) found a different RNLI factor structure with a social subscale (five items) and a physical subscale (six items).

A possible explanation for the factor structure differences could be the fact that the current study utilised a homogeneous sample comprising of only PLWSCI, while the Wood-Dauphinee et al (1988) and Stark et al (2005) studies used heterogeneous samples which included spinal cord injury, Multiple Sclerosis, stroke, Cerebral Palsy and poliomyelitis. Due to the different diagnoses of the participants in the previous studies, participants were likely to experience different psycho-social challenges of reintegration as a result of their different disabilities than the pure SCI diagnostic group in this study. Further studies are therefore recommended, to compare different PLWSCI with other disabling conditions within a South African context.

The content, construct, item convergent and item discriminant validity for the RNLI were established, suggesting that the instrument is a true measure community reintegration for PLWSCI. However, this psychometric analysis is based on data from a cross sectional study, time dependent aspects of validity (e.g. predictive validity) and reliability (e.g. test retest reliability) could not be established. Test retest reliability can be a challenge, especially in cases where unique characteristics such as community participation, social and recreational activities could change over the course of the time interval for the retest. Also, the specificity and the sensitivity of the instrument in this population were not determined.

\section{CONCLUSION}

The results of this study have demonstrated that the RNLI reliably measures the extent to which PLWSCI perceive their satisfaction with community reintegration. The RNLI was found to be psychometrically sound with excellent reliability coefficients. The instrument shown good item convergent and item discriminant validity, and content and construct validity. These findings suggest that the RNLI has acceptable measurement properties, and is therefore suitable for use among South Africans living with SCI.

\section{ACKNOWLEDGEMENT}

This paper reports on part of a $\mathrm{PhD}$ study conducted by DJ Mothabeng at the University of Pretoria, supervised by Dr CA Eksteen and Professor M Westaway. The study was supported by grants from the School of health care sciences at the University of Pretoria, and the Research foundation of the South African Society of Physiotherapy. The authors thank the PLWSCI who participated in the study; and management of the Tshwane rehabilitation centre and Just at Meulmed Rehabilitation for availing their facilities for this study.

\section{REFERENCES}

Andaleeb SS 2001 Service quality perceptions and patient satisfaction: a study of hospitals in developing countries. Social Science Medicine; 52: 1359-1370.

Arias E, de Vos S 1996 Using housing items to indicate socioeconomic status:Latin America Social Indicators Research 38, 53-80.

Cattell RB 1966 The scree test for the number of factors. Sociological Methods Research; $1: 245-276$.

Child D 1970 The essentials of factor analysis London: Holt, Rinehart \& Winston.

Cicerone KD, Mott T, Azulay J, Friel JC 2004 Community integration and satisfaction with functioning after intensive cognitive rehabilitation for traumatic brain injury. Archives of Physical Medicine and Rehabilitation;85:943-50.

Cronbach LJ 1970 Essentials of psychological testing, 3rd ed. New York: Harper \& Row

Daneski K, Coshall C, Tillingand $\mathrm{K}$ and Wolfe CDA (2003) Reliability and validity of a postal version of the Reintegration to Normal Living Index, modified for use with stroke patients Clinical Rehabilitation; 17: 835-839
Dijkers M 1999Correlates of life satisfaction among persons with spinal cord injury. Archives of Physical Medicine and Rehabilitation 80: 867 $-876$

George D, Mallery P SPSS for Windows Step by Step: A Simple Guide and Reference 11.0 update, 4th ed. Boston: Allyn \& Bacon, 2003.

Gorsuch RL1983. Factor Analysis, 2nd ed. Hillsdale: Erlbaum.

Kaiser HF 1974 An index of factorial simplicity. Psychometrika; 39: 31-36.

Kim J, Mueller CW 1978 Factor Analysis: Statistical Methods and Practical Issues. Series: Quantitative Applications in the Social Sciences. Sage Publications, Newbury Park.

Mothabeng DJ 2011, Community participation for people living with spinal cord injury in the Tshwane Metropolitan area, $\mathrm{PhD}$ thesis, University of Pretoria, Pretoria, viewed on 2011-07-18 from URL: <http://upetd.up.ac.za/thesis/available/ etd-06282011-134456/ >

Nunally JC 1978 Psychometric theory. 2nd ed. New York: McGraw-Hill.

Pang MYC, Eng JJ, Miller WC 2007 Determinants of satisfaction with community reintegration in older adults with chronic stroke: role of balance self-efficacy. Physical Therapy; 87:282-291.

Rosner B 1986. Fundamentals of biostatistics $2^{\text {nd }}$ ed. Boston, Massachusetts: Duxbury Press , 417-419.

Stark SL, Edwards DF, Hollingsworth H, Gray DB (2005) Validation of the Reintegration to Normal Living Index in a population of community-dwelling people with mobility limitations. Archives of Physical Medicine and Rehabilitation 86: 344-5

Streiner DL, Norman GR 1989 Health Measurement Scales - A Practical Guide to their Development and Use Oxford University Press: Oxford, pp 106-125.

Wood-Dauphinee SL, Opzoomer MA, Williams JI, Marchand B, Spitzer WO (1988). Assessment of global function: The Reintegration to Normal Living Index. Archives of Physical Medicine and Rehabilitation; 69: 583-90 